\title{
Strategy for addressing the airway in a forced lateral decubitus
}

\section{Case report}

A 17 years old male patient presented with a progressively enlarging back tumor of six months duration, prompting him to wear jackets and backpacks to conceal it from others. He had intense, continuous pain in the region, and an inability to lie down in a supine position.

Family history was negative.

Vitals signs: BP 110 /70 Pulse 80 Respiratory rate 14.

Laboratory studies: The only abnormality: hemoglobin 9gm, hematocrit $29 \%$.

Chest Xray, CT, MRI: metastatic signs, but no airway or respiratory compromise.

Electrocardiogram was normal. He was not an aspiration risk.

Except for the tumor his history and examination (neurological, too) was normal.

\section{Physical examination revealed the following}

Height $174 \mathrm{~cm}$ (66 inches), weight $76 \mathrm{~kg}$.

A fungiform-shaped tumor $28 \mathrm{~cm}$ in diameter crosswise and 20 $\mathrm{cm}$ of protrusion was located approximately between the $6^{\text {th }}$ and $12^{\text {th }}$ thoracic levels. The surface of the lesion and nearby tissues had inflammatory and necrotic areas.

Palpation was painful and the consistency was hard, immobile and it did not shift on its flat, level base, which was indurated with penetration into the paraspinal tissues (Figure 1).

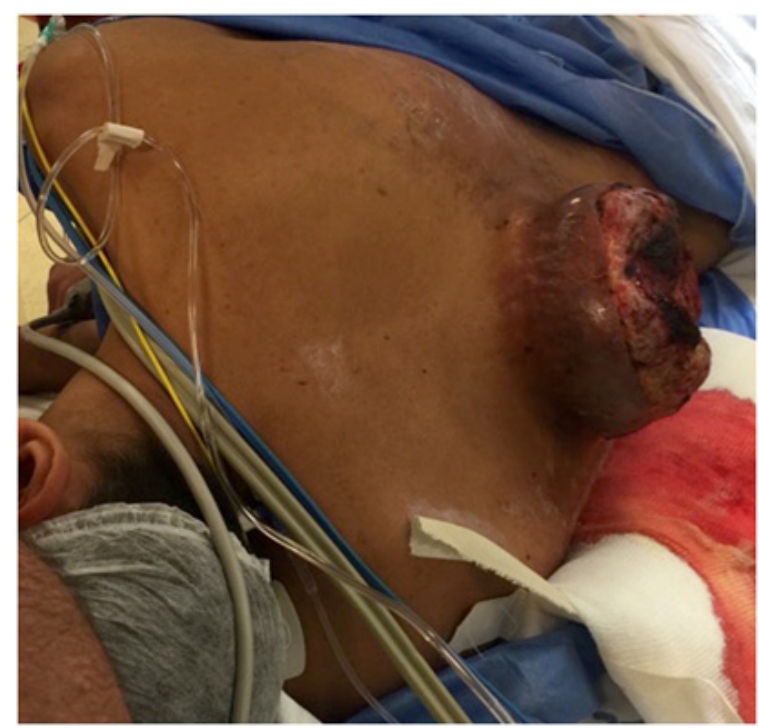

Figure I Dorsal tumor.
Volume 5 Issue 2 - 2016

\author{
Guiillermo Navarro, ${ }^{1,2}$ Rubén Allori ${ }^{3}$ \\ 'Director of the Difficult Airway Chapter of "Confederación \\ Latinoamericana de Sociedades de Anestesia" (CLASA), \\ Argentina \\ ${ }^{2}$ Director of the EVALa Group, Teaching Airway Management in \\ Latin America, Argentina \\ ${ }^{3}$ Hospital de Emergencias Clemente Álvarez (HECA) Rosario, \\ Argentina
}

Correspondence: Guiillermo Navarro, Director del Capítulo de Vía Aérea Difícil de la Confederación Latinoamericana de Sociedades de Anestesia (CLASA), Director del Grupo Entrenamiento en Vía Aérea Latinoamérica (EVALa),Argentina, Email gnavarro@anestesia.org.ar

Received: January 28, 2016 | Published: July 0I, 2016

\section{Airway examination}

There were no predictors related to any difficulty for mask ventilation, supraglottic device usage, direct laryngoscopy or video laryngoscopy, except - it was impossible for him to adopt a supine position, and in fact, he had to be angled at more of a lateral decubitus than normal 90 degrees. Our preference was for the left side down (in case direct laryngoscopy was needed, so that the tongue would fall downward and away from the right side of the mouth) (Figure 2). The patient was scheduled for surgical reduction of the mass to improve his level of comfort.

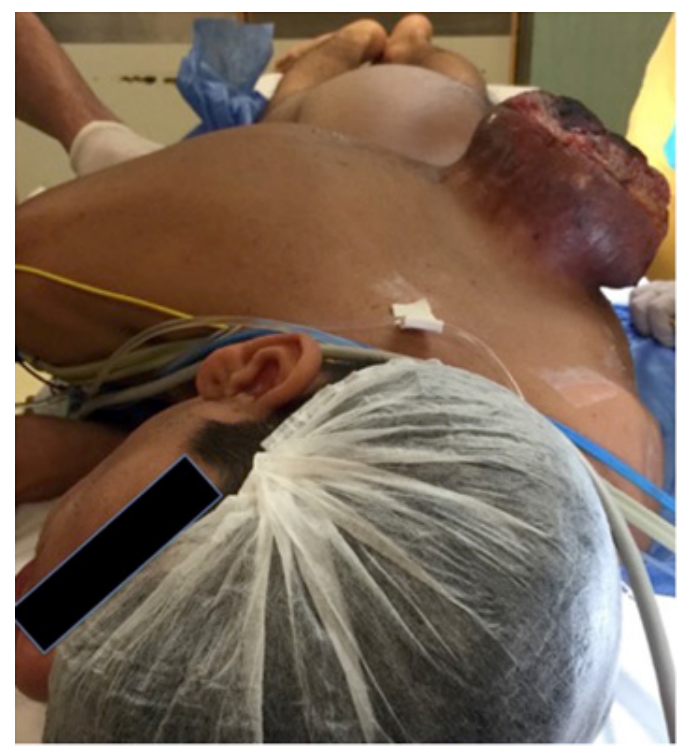

Figure 2 Left lateral decubitus. 


\section{Anesthetic airway strategy}

a. The first plan's target was for tracheal intubation under general anesthesia and abolition of ventilation.

b. We chose to control ventilation and intubate with the Totaltrack ${ }^{\circledR}$ Video Laryngeal Mask System (Totaltrack VLM) because the mask is easy to insert in strange positions.

c. An alternative was to induce general anesthesia and intubate with a GlideScope ${ }^{\circledR}$ videolaryngoscope.

d. A second plan was to control ventilation and oxygenation with a second generation supraglottic device: ProSeal ${ }^{\circledR}$ Laryngeal Mask Airway (LMA), LMA Supreme, ${ }^{\circledR} I-G e l,{ }^{\circledR}$ or use the mask part of the Totaltrack.

e. A third plan was to use a face mask, and employ two operators for handling the mask and ventilation bag, while keeping in mind the likelihood for using oropharyngeal airways, optimizing maneuvers, and muscle relaxation.

f. A fourth plan was to use an infraglottic device (surgical airway). Plans: if needed.

\section{Anesthetic course}

In the pre-anesthetic room, the patient was placed in the left lateral decubitus position with a well-functioning intravenous (IV). He was premedicated with IV midazolam $0.04 \mathrm{mg} / \mathrm{kg}$ and given oxygen by a supplementary mask (50\%). In the operating room, ECG, pulse oximetry, and non-invasive blood pressure were monitored. He was pre-oxygenated with a simple facial mask $(100 \%)$ for three minutes (Figure 3). Induction proceeded with intravenous propofol $2.5 \mathrm{mg}$ kilo, remifentanil $0.3 \mu \mathrm{g} / \mathrm{kg} /$ minute, vecuronium $0.8 \mathrm{mg} / \mathrm{kg}$.

A VLM number 4 was inserted uneventfully (Figure 4) and the mask was inflated up to $60 \mathrm{~cm}$ pressure. Ventilation was accompanied by ETCO2 25-35mmHg, and visual capnograms with consecutive normal morphology. The glottis was located on the screen (Figure 5) and we proceeded to intubate the trachea while obtaining capnographic recordings (Figure 6).

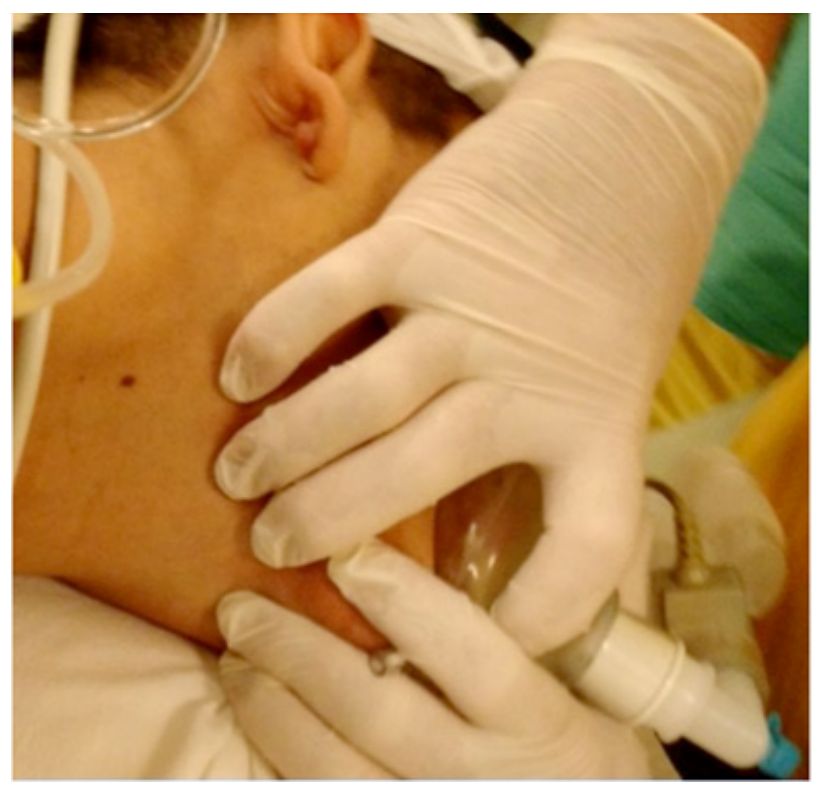

Figure 3 Preoxygenation 3 minutes.

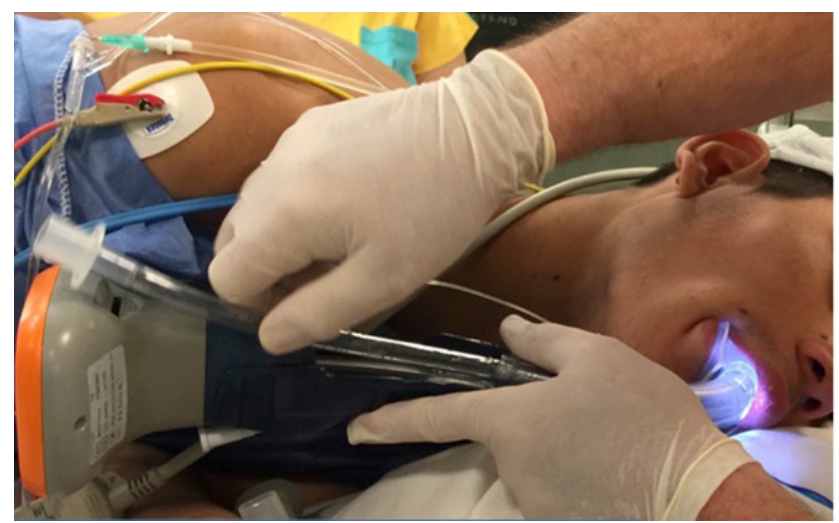

Figure 4 Total track insertion mode VLM “Mascara”.

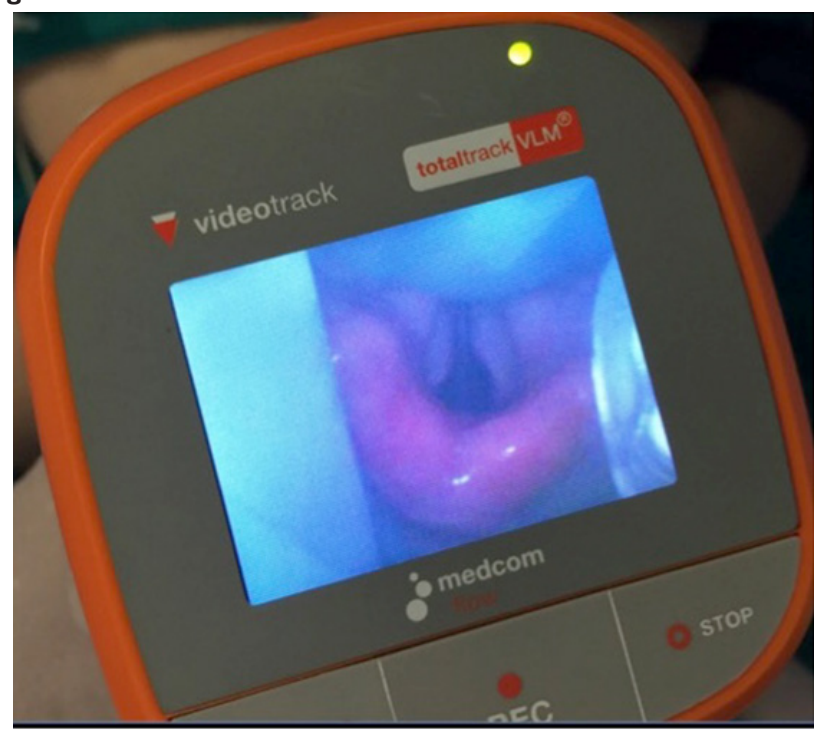

Figure $\mathbf{5}$ Location of the glottis in the video track.

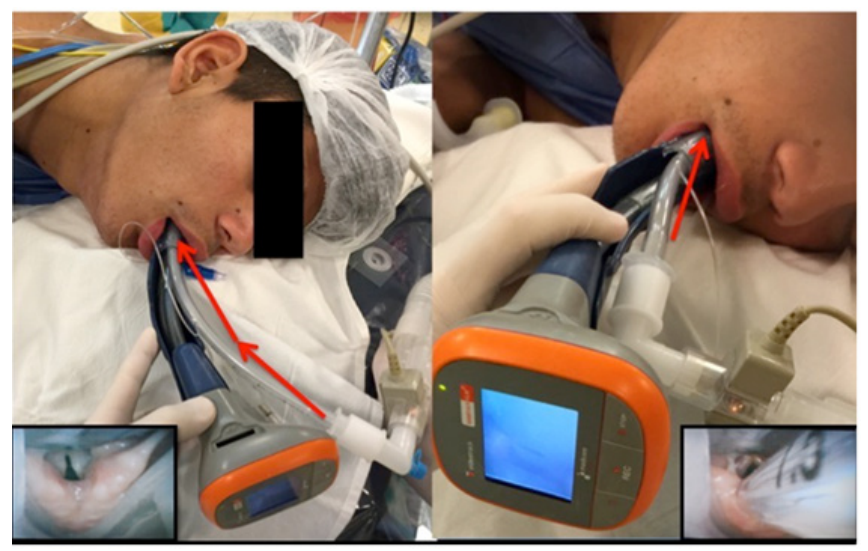

Figure 6VLM total track Mode "intubation".

Once the endotracheal tube was situated in the correct space, it was held firmly in place and the VLM was withdrawn. The surgery proceeded according to plan with excision of the tumor to a great extent uneventfully (Figure 7). Subsequently, the patient was sent extubated, awake, ventilating satisfactorily, and hemodynamically stable to the recovery room. 


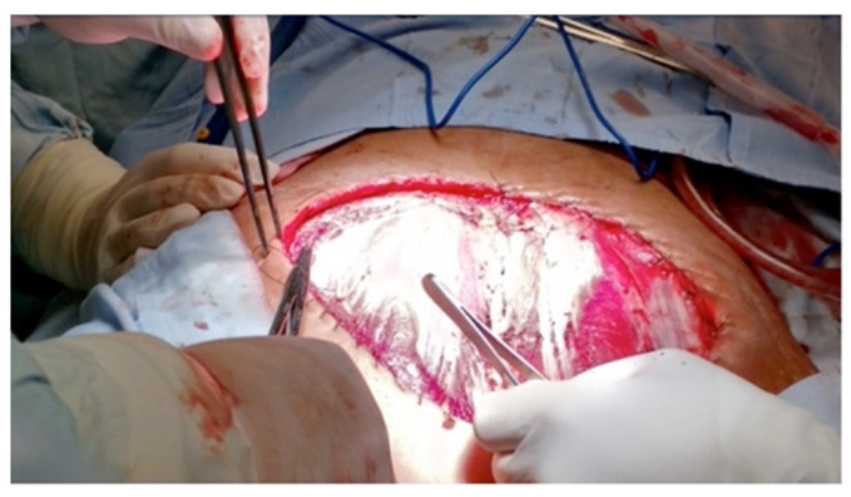

Figure 7 Respected tumor.

\section{Discussion}

The physical examination of the patient's airway, did not give any prediction of difficulty in addressing it. The forced decubitus position prompted the reason for the selection of a Video Laringeal Mask. Total track VLM was chosen for the following reasons:

1. Ease of insertion of the laryngeal mask when patients are in positions that are not supine.

2. Control of ventilation with continuous oxygenation by the laryngeal mask insertion (with monitoring for normal consecutive capnograms).

3. Continuous vision through the videotrack, identification of the airway and vocal cords without interrupting ventilation, oxygenation, and administration of anesthetic gas.

4. Intubation under continuous vision of the laryngeal anatomy. The intubation was performed in less than two minutes and there was no need for stopping ventilation of the patient during that time.

Multiple alternatives always remained available for our overall strategy. We adopted the algorithm of the DAS: a strategy of four plans, where only our plan 1 aimed for "intubation." Our remaining plans: 2, 3 and 4 essentially would have been to maintain oxygenation by different specific actions. ${ }^{1}$ One of the few studies on tracheal intubation in the lateral position in patients with normal airway anatomy found that the Intubating Laryngeal Mask Airway® (ILMA) had a similar success rate and time required for blind intubation in the lateral versus supine positions. ${ }^{2}$

\section{Conclusion}

The Video Laringeal Mask is a new device with a bimodal functional concept to control the airway in different clinical scenarios. The initial operating mode is called "Mask" and the secondary is "Intubation." It is interesting to note the ability to operate in mask mode ventilation and oxygenation may be possible at the same time as the ability to view continuously, the airway and laryngeal structures, and to facilitate the final tracheal intubation.

\section{Acknowledgments}

None.

\section{Conflicts of interest}

The authors declare there is no conflict of interests.

\section{Funding}

None.

\section{References}

1. Frerk C, Mitchell VS, McNarry AF, et al. Difficult airway society intubation guidelines working group. 2015 Difficult Airway Society guidelines for management of unanticipated difficult intubation in adults. Br J Anaesthesia. 2015;115(6):827-848.

2. Komatsu R, Nagata O, Sessler DI, et al. The intubating laryngeal mask airway facilitates tracheal intubation in the lateral position. Anesth Analg. 2004;98(3):858-861. 